\title{
Simulation Study of Mixed Pressure and Flow Control Systems for Optimal Operation of Centrifugal Pumping Plants
}

\author{
Levon Gevorkov* (Researcher, Tallinn University of Technology, Tallinn, Estonia), \\ Anton Rassõlkin (Researcher, Tallinn University of Technology, Tallinn, Estonia), \\ Ants Kallaste (Senior Researcher, Tallinn University of Technology, Tallinn, Estonia), \\ Toomas Vaimann (Senior Researcher, Tallinn University of Technology, Tallinn, Estonia)
}

\begin{abstract}
A Simulink/DriveSize based model for the mutual pressure and flow control of a centrifugal pumping plant with a variable speed drive is proposed. The model provides the possibility of power calculation during both throttling and speed control and to estimate the optimal working point according to these calculations. The model is developed to provide the possibility of power reduction during pressure and flow maintenance with the help of mixed pressure control strategy. To evaluate the system, a series of experiments have been conducted. After the validation of the proposed model through testing, which proved that the designed system is more beneficial from the power consumption point of view than the traditional pressure control methods, it can be stated that the system is useful for pressure and flow control optimization of the centrifugal pumping plants.
\end{abstract}

Keywords - Centrifugal pump; MATLAB; Modelling; Power measurement; Variable speed drive.

\section{INTRODUCTION}

Centrifugal pumps play a key role in the modern water supply industry, distribution and sewerage networks by providing the vast amount of drinkable and raw water for industrial, household and commercial applications [1], [2]. The growth of concentration of population in big cities leads to the necessity of larger and more complicated water supply and distribution systems [3], [4]. These water distribution systems are using various control methods to achieve high productivity and the reduction of energy consumption [5]. Growing concerns about the increased greenhouse gas emission and high costs of the electrical energy production are urgent calls for optimization of existing and newly developed pumping systems [6].

Several approaches have been developed to investigate the possibilities of optimization of pumping systems [7]. In accordance to [8], the so-called objective function $J$ of the optimal operation of a centrifugal pump station can be expressed as follows:

$$
J=\sum_{e} \int_{t_{i}}^{t_{f}}\left[c_{e} Q_{e}(t)+\frac{b_{e} H_{e}(t) Q_{e}(t)}{\eta\left(Q_{e}(t)\right)}\right] d t,
$$

where

$e$ a particular pump of multi-pump system;

$t_{\mathrm{i}}$ initial time of operation, $\mathrm{s}$;

$t_{\mathrm{f}}$ final time of operation, $\mathrm{s}$;

$c_{e}$ unit cost of water production;

$b_{e} \quad$ unit price of energy;

$Q_{e}(t) \quad$ flow of the pump, $\mathrm{m}^{3} / \mathrm{h}$;

$H_{e}$ energy head, m;

$\eta\left(Q_{e}(t)\right)$ efficiency.

This equation comprises the dependences of flow and head that are related by a non-linear function. The flow can be described by a discrete variable for a fixed velocity and system condition or as a continuous variable depending on the speed rate of the throttling of a pump. Equation (1) represents a dynamic, non-linear system. Despite many attempts to find a general solution, there is still no progress. Due to the fact, that the general solution is not found yet, it is necessary to develop the adaptive and simplified optimization approaches. This task can be solved by investigating the particular characteristics of the centrifugal pump systems.

As a rule, in a water distribution network, the fluid flow and head do not change rapidly during the main operation period. Wide range disturbances of flow and head are usually caused by emergencies in water supply network or sewerage system. Therefore, the demand variation from the intake part of a network can be compensated by variations of pump rotational speed or throttling. These two types of regulation are the main control methods for pressure and flow in centrifugal pumping plant system. One of the main considerations is the energy consumption of the pumping plant system during throttling and speed adjustment. The pumping cost heavily depends on the consumed power [8]:

$$
\operatorname{Cost}_{e}=\sum_{e} P(U C) T=\sum_{e}\left(\frac{\rho g H Q}{\eta}\right)(U C) T,
$$

* Corresponding author.

E-mail: levon.gevorkov@ttu.ee 
where

$\begin{array}{ll}P & \text { pump power, } \mathrm{W} \\ U C & \text { electricity unit cost; } \\ T & \text { time duration, } \mathrm{s} ; \\ \rho & \text { liquid density, } \mathrm{kg} / \mathrm{m}^{3} ; \\ g & \text { acceleration due to gravity, } \mathrm{m} / \mathrm{s}^{2} ; \\ \eta & \text { efficiency of a pump. }\end{array}$

According to this equation, the pumping cost is proportional to the consumed power P. For the power estimation various approaches are proposed. One of the methods is a sensorbased estimation of the operational state of a centrifugal pumping system [9]. Another approach is based on the investigation of the behavior of the pump's model [10]. If the model is not complicated, an accurate analytical solution is usually available. As the system gets more complex, there are many challenges.

To explore systems that have complicated structure and to achieve better results, it is more common to study the system with the help of real prototypes or computer simulations that describe properties of the system and predict its performance. The main disadvantages of the first method are the high cost and time outlay.

On the other hand, computer modeling can help to achieve similar results in many cases by utilizing only the powerful capabilities of modern simulation hardware and software. Nowadays, there are several software toolboxes such as MATLAB/Simulink, COMSOL, or optimizers like C-Radiant, that are appropriate for these tasks [11]-[13]. The main advantage of these toolboxes lays in the time and cost saving capability in comparison with various control approaches, and optimization technologies.

There are different computer models that have been developed to investigate the behavior of centrifugal pumps [14], [15]. Unfortunately, many of the previously developed models do not consider the power losses in the electric drive of a pumping system.

To assess the energy consumption and to focus on the input power of the centrifugal pump system during valve and speed control, a Simulink/DriveSize computer model is proposed in this paper. The model is used for developed mixed pressure and flow control system.

The following section describes the main concept of the developed control methods. Then, the topology of the developed model and its subsystems is explained in details. Finally, the experimental results are shown to ensure the data obtained with the help of the developed model

\section{ENERGY ORIENTED MIXED CONTROL SYSTEM}

The power on the shaft of a single-stage centrifugal pump is given by the equation [16]:

$$
P_{\text {shaft }}=T \omega=\frac{\pi n T}{30},
$$

where

$$
\begin{aligned}
& P_{\text {shaft }} \text { brake power on the pump shaft, } \mathrm{W} ; \\
& \omega \quad \text { rotational speed, } \mathrm{rad} / \mathrm{s} ; \\
& T \quad \text { pump torque, } \mathrm{Nm} ; \\
& n \quad \text { rotational speed of the pump, rpm. }
\end{aligned}
$$

Pump manufacturing companies usually provide technical description with main characteristics of the centrifugal pump, such as head-flow $(H-Q)$ curves, efficiency-flow $(\eta-Q)$ curves and power-flow $(P-Q)$ curves. As it was shown, due to the complex and non-linear dependences between main pump characteristics, it is quite difficult to use analytical solutions to explain these dependences. Therefore, the empirical dependences, given by the manufacturing company, help to describe the characteristics of the centrifugal pump system and predict the behavior of system during different control operation modes. To study the centrifugal pump system with the help of simulation methods, we can use the mentioned dependences between main characteristics to build the look up tables.

Dependences between main pump characteristics are given in Fig. 1. The cross section of the centrifugal pump performance curve and system curve marks the position of the working point. $W_{\mathrm{r}}$ is a working point for a rated speed. $W_{+}$, $W_{1}$ and $W_{2}$ are working points at throttling and speed control, respectively. Working points denote the main characteristics of the system as flow, energy head, pressure, efficiency and others. $Q_{\mathrm{BEP}}$ and $p_{\mathrm{BEP}}$ are values of pressure and flow for socalled best efficiency point corresponding to $W_{\text {r. }} Q_{+}$and $Q_{-}$are values of flow corresponding to $W_{1}, W_{2_{-}}$and $W_{+} . \Delta P_{1}$ and $\Delta P_{2}$ are power drops during throttle and speed control.

The full input power of a centrifugal pump system is given by the equation

$$
P_{\text {in }}=P_{\text {loss }}+P_{\text {shaft }} \text {. }
$$

$P_{\text {loss }}$ is the amount of power losses caused by an electric drive of a centrifugal pumping plant. To implement more flexible and beneficial from an energy point of view control system, a so-called mixed control strategy was developed. The control system was tested with the help of real experimental setup. 


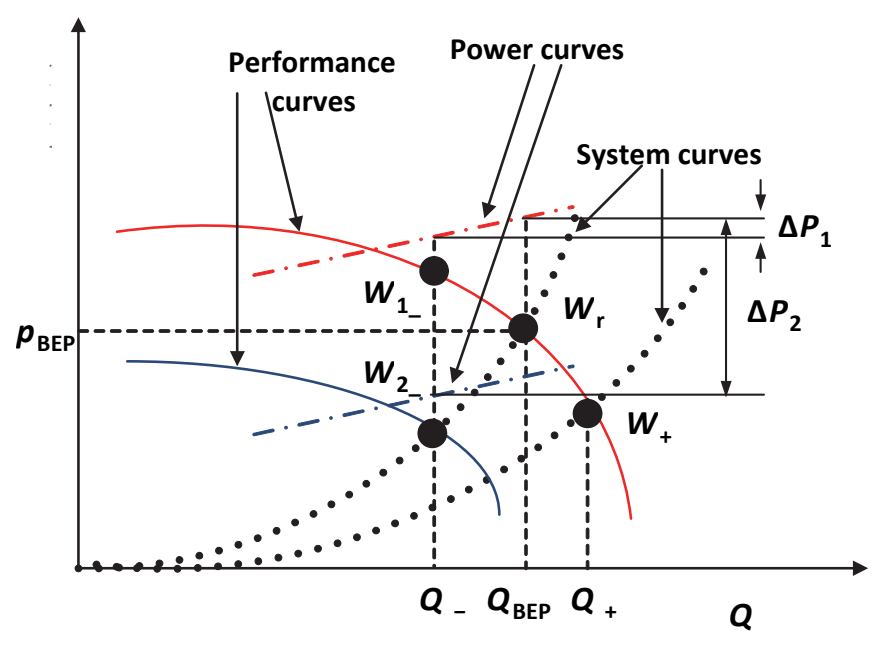

Fig. 1. Main characteristics of a centrifugal pump.

The algorithm of the developed control system is shown in Fig. 2. In the beginning, the program initializes arguments of the functions, as well as checks the connection between PLC, frequency converter and a terminal of a real experimental setup. Then the initial data is uploaded from the lookup tables and program checking of the rotational speed of a pump and valve control position. The actual speed $n_{\text {act }}$ and actual angle $\alpha_{\text {act }}$ are the parameters that the program receives from the frequency converter, which is connected to the PLC via the profibus adapter FPBA-01 and encoder. Starting from zero, it should reach at least the minimum value of $500 \mathrm{rpm}$ and the valve should be opened at least to 60 degrees. If the condition is not right, the program starts recursion and increases the speed value and the valve angle until it reaches up to the minimum level.

Then the program proceeds to the next step. In this step, the algorithm begins to estimate the input power of a centrifugal pump system for a mixed pressure control, based on the value of a reference pressure signal. After completing the calculations, the algorithm appoints the most optimal working point position and calculates the appropriate valve position and the rotational speed of a pump that are corresponding to the particular working point. The values of the throttling valve and rotational speed are sent to the next part of the program. With the help of these calculations, it becomes possible to adjust the working point exactly in the most efficient region from energy point of view and to obtain the highest efficiency of the operation at the same time reducing input power consumption by the centrifugal pumping system.

In the next step, the value of the actual speed $n_{\text {act }}$ and valve angle $\alpha_{\text {act }}$ are compared with the reference value $n_{\text {ref }}$ and $\alpha_{\text {ref }}$, then the PID controls an output speed of the centrifugal pump Ebara CDX [17] and the valve position. In the last step, the system checks the pressure value from pressure sensor MBS3000. If an actual pressure value exceeds the limits, the program stops the centrifugal pump. In the case when the actual pressure value is within these borders, the algorithm is not interrupted.

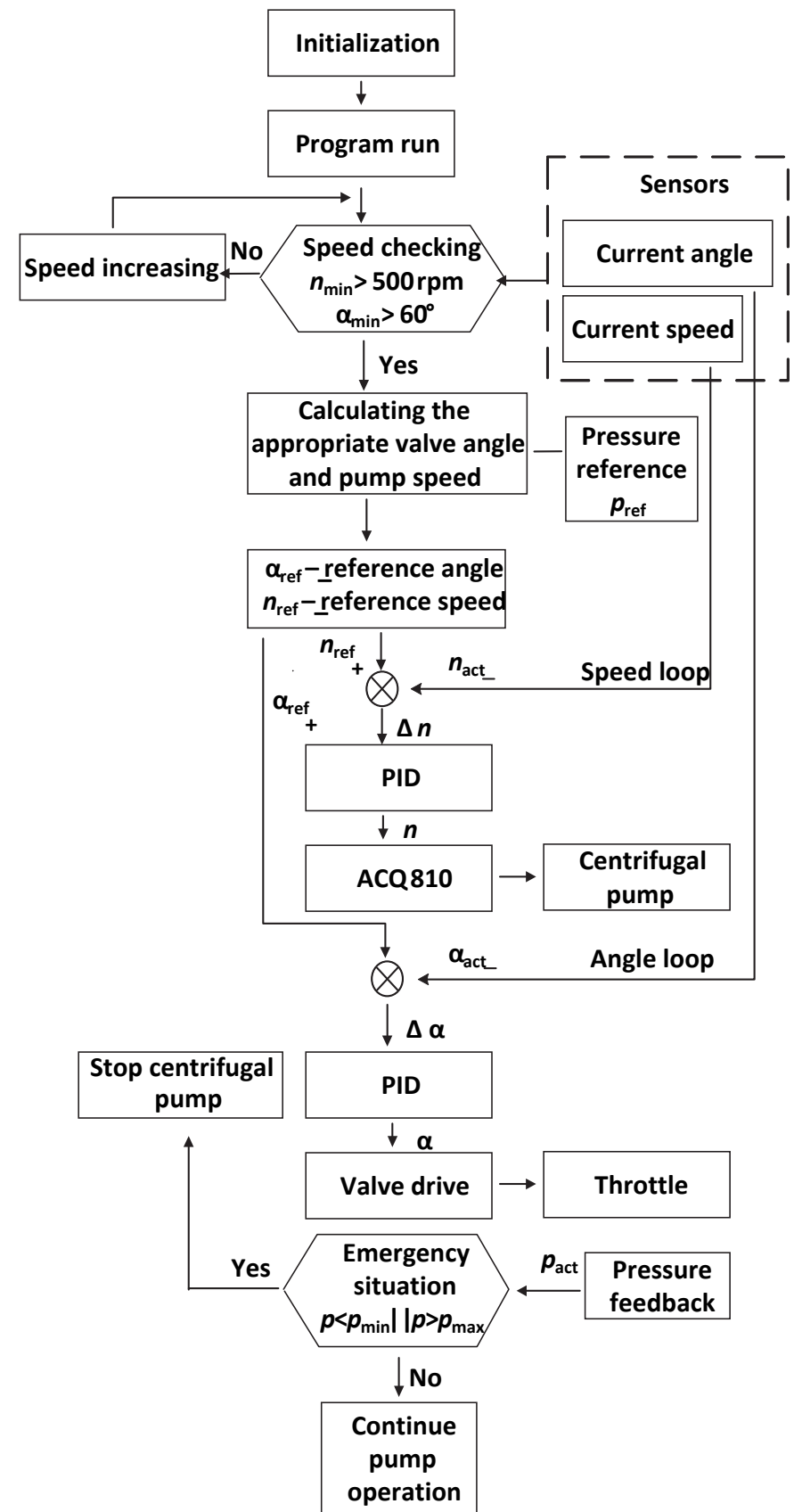

Fig. 2. Mixed control algorithm for a centrifugal pumping plant.

\section{Model of MiXed Pressure AND Flow CONTROL SySteM}

The general structure of the developed model helps to simulate the mixed pressure and flow control system described above. The full structure of the model is shown in Fig. 3.

The model consists of three main parts. The first part is designed to process the input values, Fig. 4. It has the input values of pressure 1 and pressure 2 that define the input pressure range. In addition, the input values of flow 1 and flow 2 define the flow range of the model. The second part is a model of the centrifugal pump [18], and the third part is a power estimation module, which helps to calculate the total input power taking into consideration drive losses, Fig. 5. 


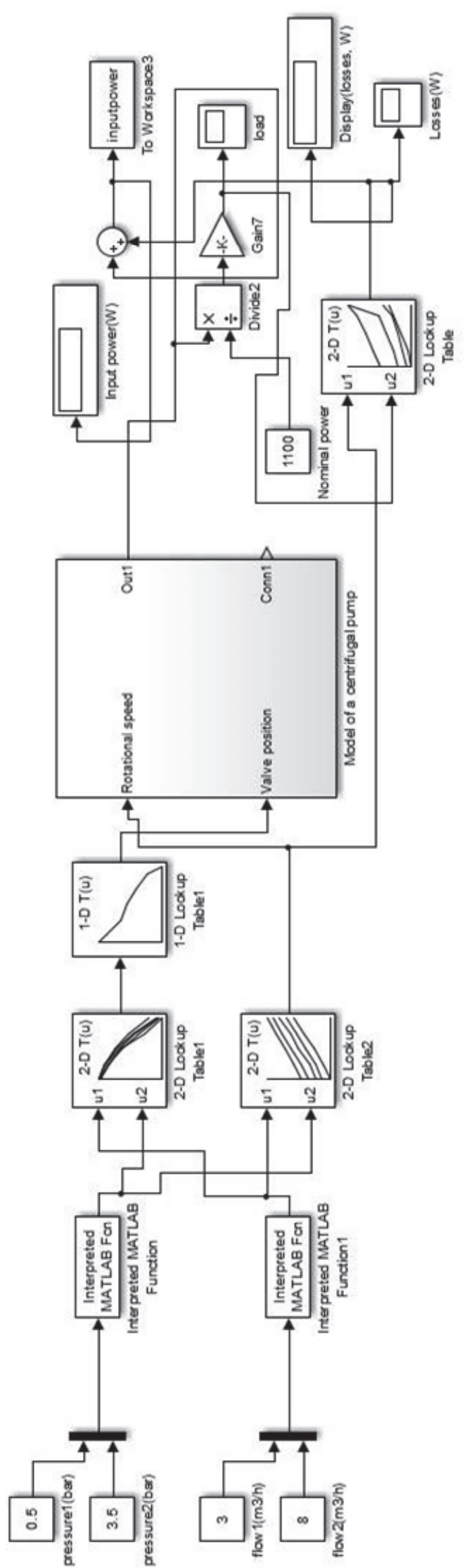

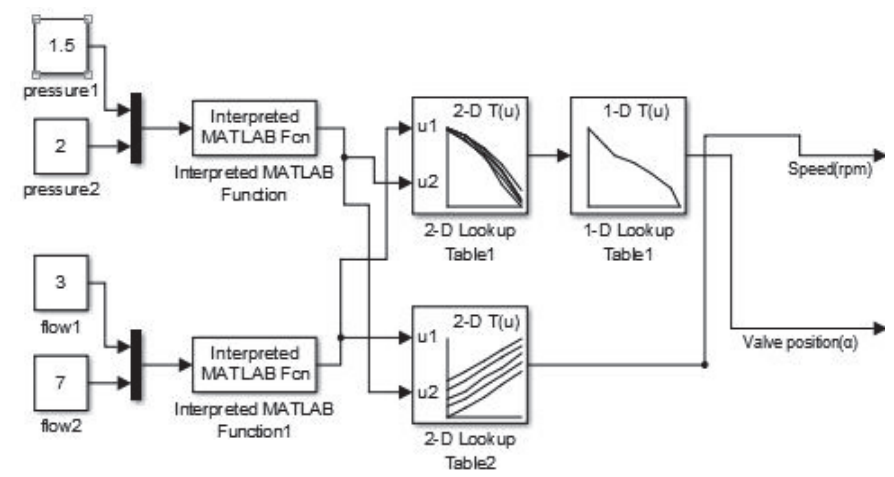

Fig. 4. The input terminal of the model.

To calculate the appropriate rotational speed of the centrifugal pump and corresponding valve position, a special MATLAB code has been developed. The script processes the input data concerning pressure and flow range and the result is sent back to the model.

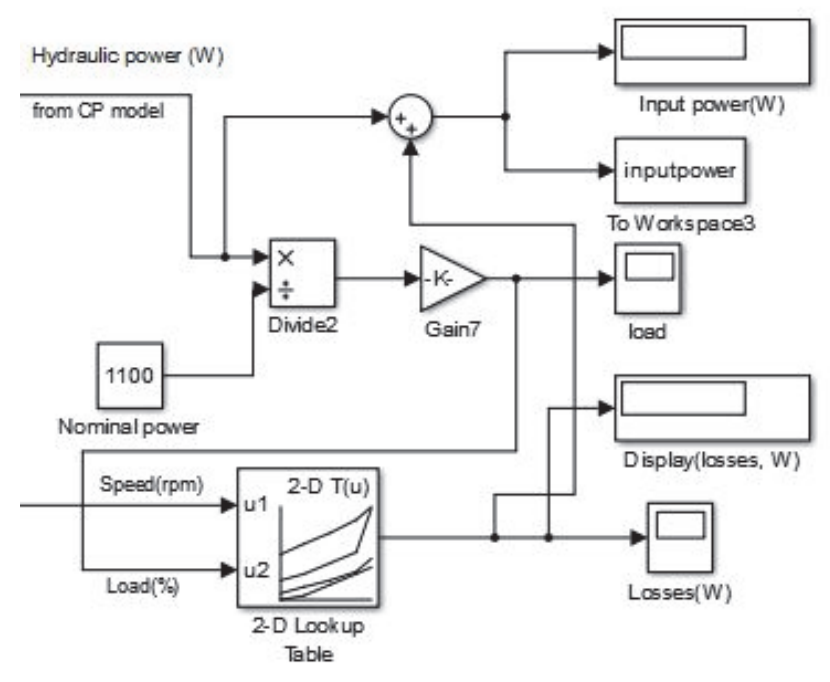

Fig. 5. Power estimation module.

The model combines two simulation environments based on Simulink and DriveSize. At first, data is entered with the help of constants: pressure 1, pressure 2, flow1, flow2. Thus it becomes possible to define the operating region. Then the program calculates the appropriate speed and valve position according to the defined operating region.

Then, with the help of the centrifugal pump model the hydraulic power and power on the shaft are calculated, and based on the data from DriveSize software the input power is obtained. The data later is presented in the form of look-up tables. The model allows to simulate the behavior of the mixed control system and at the same time to find the possible ways for its optimization.

\section{EXPERIMENTAL VERIFICATION}

To validate the model accuracy the real experimental setup was used [19]. The experimental setup consists of several main parts shown in Fig. 6.

Fig. 3. Model of the mixed control system for a centrifugal pump. 


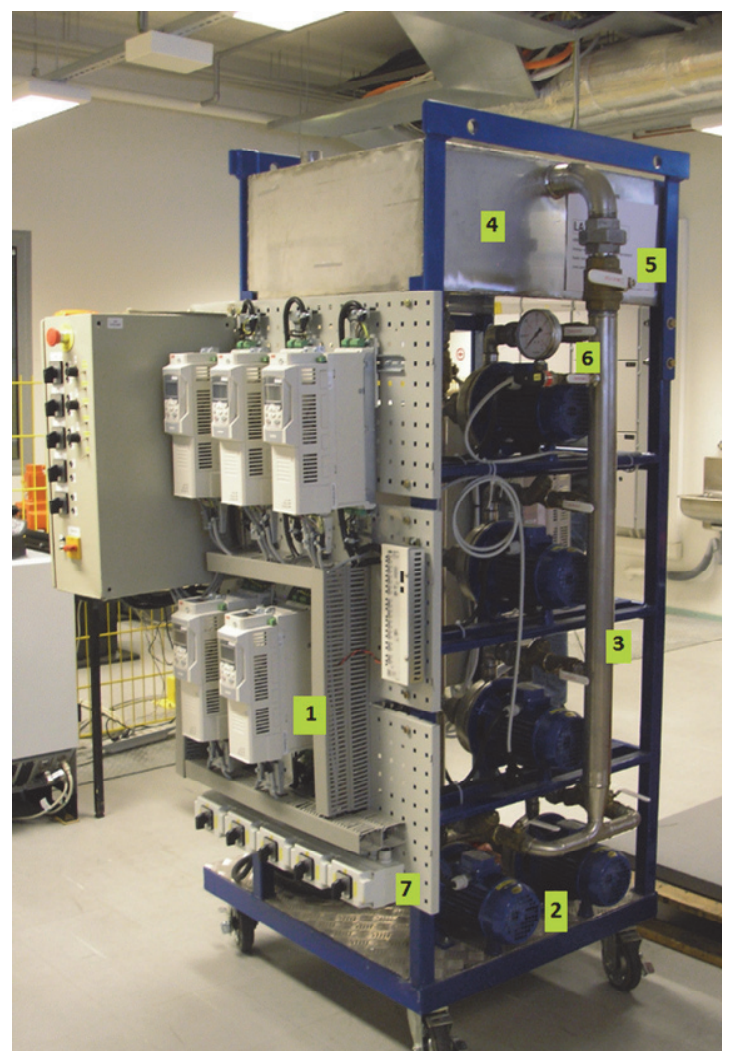

Fig. 6. Experimental setup: (1) ACQ810 frequency converter; (2) EbaraCDX120/12 centrifugal pump; (3) pipeline with 2-inch inner diameter; (4) fluid reservoir; (5) throttling valve; (6) pressure sensor.

To estimate the consumed power of the centrifugal pump system during mixed throttling and speed control, several procedures were applied. First, the system was examined within the boundaries limited by the input values of pressure and flow, and then the speed of the pumping system was adjusted with the help of VSD, while the system curve was controlled with the help of valve position. The working point of the centrifugal pumping plant was adjusted in accordance with the parameters received from the model.

The system was examined within the boundaries of the liquid flow from $2 \mathrm{~m}^{3} / \mathrm{h}$ to $10 \mathrm{~m}^{3} / \mathrm{h}$. The experimentally obtained system curves for a range of different rotational speeds are shown in Fig. 7.

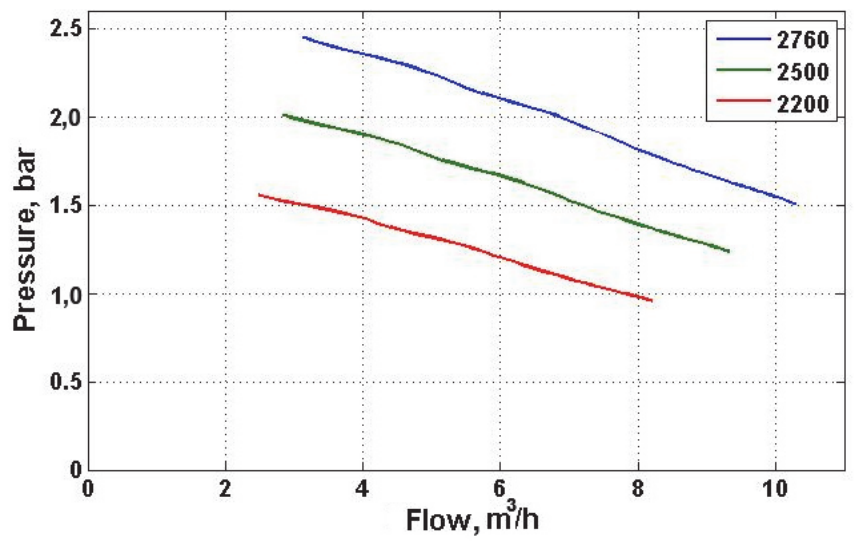

Fig. 7. Performance curves for different rotational speeds for EbaraCDX120/12.
The table contacting comparative data for the input power of a centrifugal pumping plant for simulation and experimentation during mixed control, at the pressure level of 1.8 bar is shown in Table I.

TABLE I

COMPARISON OF ESTIMATED POWER FOR PRESSURE 1.8 BAR

\begin{tabular}{|r|r|r|r|}
\hline $\begin{array}{c}\text { Mixed } \\
\text { control }\end{array}$ & \multicolumn{2}{|c|}{ Input Power, W } & \multirow{2}{*}{ Hydraulic Power, W } \\
\cline { 1 - 2 } Flow $\left(\mathrm{m}^{3} / \mathrm{h}\right)$ & Simulation & Experimantation & \\
\hline 7.0 & 1100 & 1030 & 353 \\
\hline 6.0 & 1000 & 960 & 302 \\
\hline 5.0 & 870 & 820 & 252 \\
\hline 3.5 & 700 & 650 & 176 \\
\hline 2.5 & 540 & 510 & 126 \\
\hline
\end{tabular}

The difference between experimental and simulation results can be explained by taking into account the characteristics of the centrifugal pump. The centrifugal pump model is based on the parameters of its performance and power curves, see Fig. 3.

The comparative diagram of estimated power consumption at the flowrate of $7 \mathrm{~m}^{3} / \mathrm{h}$ is shown in Fig. 8 .

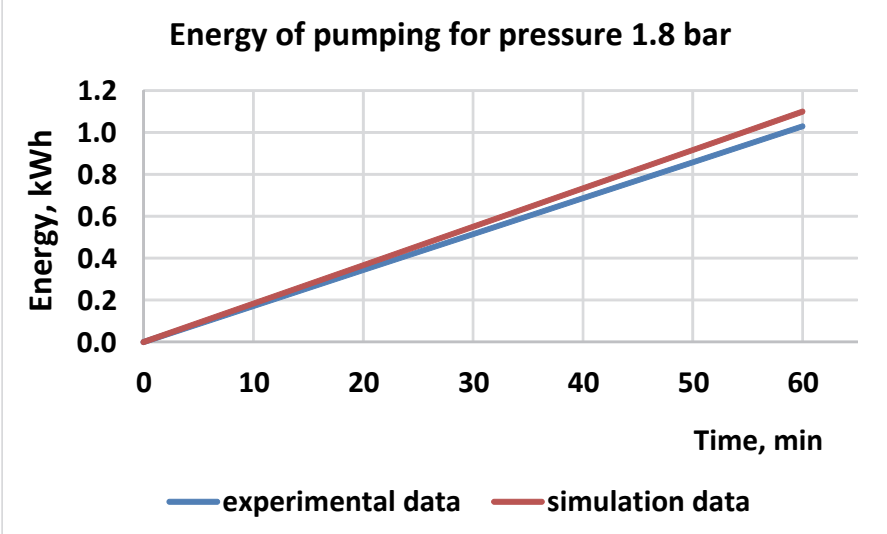

Fig. 8. Consumed power of the centrifugal pump measured by using simulation and experimental methods.

\section{CONCLUSION}

A new DriveSize/Simulink model for the mixed control system is proposed in the paper. The developed model was validated with the help of a real experimental setup. The conducted tests show that the model has a high accuracy at various simulation modes that are corresponding to the processes taking place in real centrifugal pump systems. The main advantage of the model lies in the possibility of power calculation during both throttling and speed flow control and defining the optimal working point. The novelty of the model is based on the possibility to combine data obtained from the two simulation environments. In addition, the model can be a part of the control system for a centrifugal pump. This shows that the developed model can be used in the design stage for power estimation and drive sizing. 
The assessment of data obtained during the conducted tests proves that the new approach based on mixed control can lead to energy savings during pressure and flowrate regulation.

\section{REFERENCES}

[1] I. J. Karassik and T. McGuire (Eds.), Centrifugal Pumps. Springer Science \& Business Media, 1998, $780 \mathrm{p}$. https://doi.org/10.1007/978-1-4615-6604-5

[2] L. Nelik, Centrifugal and Rotary Pumps: Fundamentals With Applications. CRC Press, 1999, $152 \mathrm{p}$

[3] D. E. Agthe, R. B. Billings, and N. Buras, Managing Urban Water Supply. Springer Science \& Business Media, 2013, 277 p. https://doi.org/10.1007/978-94-017-0237-9

[4] D. J. Anton, Thirsty Cities: Urban Environments and Water Supply in Latin America. IDRC, 1993, 197 p.

[5] F. Parasiliti and P. Bertoldi, Energy Efficiency in Motor Driven Systems. Springer Science \& Business Media, 2003, 565 p. https://doi.org/10.1007/978-3-642-55475-9

[6] F. J. T. E. Ferreira, J. A C. Fong, and A. T. De Almeida, "Ecoanalysis of Variable-Speed Drives for Flow Regulation in Pumping Systems," IEEE Transactions on Industrial Electronics, vol. 58, no. 6, Jun. 2011, pp. $2117-2125$

[7] T. Rauschenbach (Ed), Modeling, Control and Optimization of Water Systems: Systems Engineering Methods for Control and Decision Making Tasks. Springer, 2015, $303 \mathrm{p}$ https://doi.org/10.1007/978-3-642-16026-4

[8] Y. C. Chen and B. Coulbeck, "Optimized Operation of Water Supply Systems Containing a Mixture of Fixed and Variable Speed Pumps," in International Conference on Control. Control 1991, Edinburgh, 25-28 Mar., 1991, pp. 1200-1205.

[9] L. Gevorkov, A. Rassõlkin, A. Kallaste, and T. Vaimann, "Simulink Based Model for Flow Control of a Centrifugal Pumping System," in 2018 25th International Workshop on Electric Drives: Optimization in Control of Electric Drives (IWED), Moscow, Russia, Jan. 2018, pp. 1-4. https://doi.org/10.1109/iwed.2018.8321399

[10] L. Gevorkov, A. Rassõlkin, A. Kallaste, and T. Vaimann, "Simulation Study of a Centrifugal Pumping Plant's Power Consumption at Throttling and Speed Control," in 2017 IEEE 58th International Scientific Conference on Power and Electrical Engineering of Riga Technical University (RTUCON), Riga, Latvia, 12-13 Oct., 2017, pp. 1-5. https://doi.org/10.1109/rtucon.2017.8124823

[11] A. Boussaibo, M. Kamta, J. Kayem, D. Toader, S. Haragus, and A. Maghet, "Characterization of Photovoltaic Pumping System Mode Without Battery Storage by MATLAB/Simulink," in 9th International Symposium on Advanced Topics in Electrical Engineering, Bucharest, Romania, 7-9 May, 2015, pp. 774-780. https://doi.org/10.1109/atee.2015.7133907

[12] D. Al-Ani and S. Habibi, "Optimal Pump Operation for Water Distribution Systems Using a New Multi-Agent Particle Swarm Optimization technique With EPANET," in 2012 25th IEEE Canadian Conference on Electrical \& Computer Engineering (CCECE), Montreal, QC, 2012, pp. 1-6. https://doi.org/10.1109/ccece.2012.6335031

[13] M. Lopez-Ibanez, T. Devi Prasad, and B. Paechter, "Multi-Objective Optimisation of the Pump Scheduling Problem Using SPEA2," in 2005 IEEE Congress on Evolutionary Computation, Edinburgh, Scotland, 2005, pp. 435-442. https://doi.org/10.1109/cec.2005.1554716

[14] J. Ghafouri and H. Khayatzadeh, "Dynamic Modeling of Variable Speed Centrifugal Pump Utilizing MATLAB/Simulink," International Journal of Science and Engineering Investigations, vol. 1, no. 5, pp. 1-7, Jun. 2012.

[15] P. B. Narayana, B. R. S. Reddy, P. Motepalli, and S. Dubey, "Design and simulation of solar DC pump in Simulink," in International Conference on Energy Efficient Technologies for Sustainability (ICEETS), Nagercoil, India, 10-12 Apr., 2013, pp. 429-431. https://doi.org/10.1109/iceets.2013.6533421

[16] D. Kaya, E. A. Yagmur, K. S. Yigit, F. C. Kilinc, A. S. Eren, and C. Celik, "Energy Efficiency in Pumps," Energy Conversion and Management, vol. 49, no. 6, pp. 1662-1673, Jun. 2008 https://doi.org/10.1016/j.enconman.2007.11.010

[17] EBARA, Centrifugal Pumps CDX. [Online]. Available at: http://ebara-pumps-online.com/CDX.pdf [Accessed: 5 Jul. 2018]

[18] L. Gevorkov, I. Bakman, and V. Vodovozov, "Hardware-in-the-Loop Simulation of Motor Drives for Pumping Applications," in 2014 Electric Power Quality and Supply Reliability Conference (PQ), 11-13 Jun., 2014, pp. 203-208. https://doi.org/10.1109/pq.2014.6866811
[19] I. Bakman, "High-Efficiency Predictive Control of Centrifugal MultiPump Stations With Variable-Speed Drives," Ph. D. thesis, TTU, Tallinn, 2016, 149 p. [Online]. Available at: http://digi.lib.ttu.ee/i/?55352 [Accessed: 5 Jul. 2018].

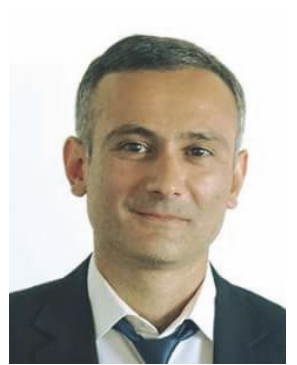

Levon Gevorkov is a researcher at Tallinn University of Technology. He received the B. sc. and M.sc. degrees in Radio-physics and Electronics from the Ivane Javakhishvili State University of Tbilisi, in 2001 and 2003, respectively.

He received his $\mathrm{Ph}$. D. degree in Electric Drives and Power Electronics in 2017 from Tallinn University of Technology. His main scientific interests lay in the field of electric drives, pumping systems.

Department of Electrical Power Engineering and Mechatronics, Tallinn University of Technology, Ehitajate tee 5, 19086 Tallinn, Estonia.

E-mail: levon.gevorkov@ttu.ee

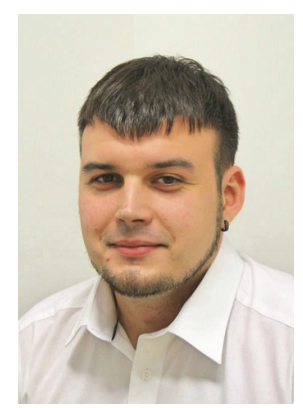

Anton Rassõlkin received a $\mathrm{Ph}$. D. deegre in Electric Drives and Power Electronics from Tallinn University of Technology in 2014. His main research interests lay in the field of electric drives and their control systems as well as in the fields of electrical machines and electric transportation.

He is currently a Researcher with the Department of Electrical Power Engineering and Mechatronics of Tallinn University of Technology. Department of Electrical Power Engineering and Mechatronics, Tallinn University of Technology, Ehitajate tee 5, 19086 Tallinn, Estonia.

E-mail: anton.rassolkin@ttu.ee ORCID iD: https://orcid.org/0000-0001-8035-3970

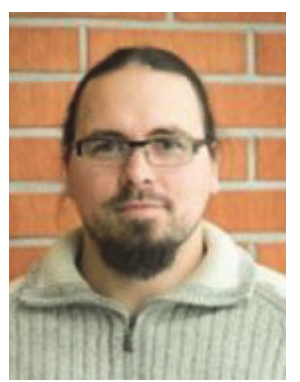

Ants Kallaste received his B. sc., M. sc. and $\mathrm{Ph}$. D. degrees in Electrical Engineering from Tallinn University of Technology, Estonia, in 2004, 2006 and 2013, respectively. He is currently a senior researcher with the Department of Electrical Power Engineering and Mechatronics of Tallinn University of Technology.

He has been working in several companies as an electrical engineer. He has been a IEEE member since 2013. His main research interests include permanent magnet machine design and wind turbines.

Department of Electrical Power Engineering and Mechatronisc, Tallinn University of Technology, Ehitajate tee 5, 19086 Tallinn, Estonia.

E-mail: ants.kallaste@ttu.ee

Orcid iD: https://orcid.org/0000-0001-6126-1878

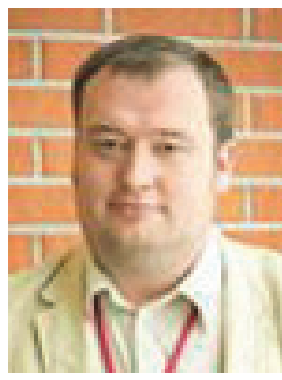

Toomas Vaimann received his $\mathrm{BSc}$, MSc and $\mathrm{Ph}$. D. degrees in Electrical Engineering from Tallinn University of Technology, Estonia, in 2007, 2009 and 2014, respectively. He is currently a senior researcher with the Department of Electrical Power Engineering and Mechatronics of Tallinn University of Technology. He has been working in several companies as an electrical engineer.

$\mathrm{He}$ is a member of IEEE, Estonian Society of Moritz Hermann Jacobi and Estonian Society for Electrical Power Engineering. His main research interests are the methods of diagnostics of electrical machines.

Department of Electrical Power Engineering and Mechatronics, Tallinn University of Technology, Ehitajate tee 5, 19086 Tallinn, Estonia.

E-mail: toomas.vaimann@ttu.ee

ORCID iD: https://orcid.org/0000-0003-0481-5066 